\title{
Aggressiveness of Fusarium Head Blight Species towards Two Modern Syrian Wheat Cultivars in an in Vitro Petri-dish
}

\author{
N. SAKR* \\ Department of Agriculture, Atomic Energy Commission of Syria, Damascus, P.O. Box 6091, Syria \\ (Received 27 July; Accepted 4 April; \\ Communicated by A. Goyal)
}

\begin{abstract}
Pathogenic variation was studied in 16 fungal isolates of four Fusarium head blight (FHB) species on two modern Syrian bread and durum wheat cultivars using an in vitro Petri-dish test. Three aggressiveness criteria: germination rate reduction, standardized area under disease progress curve $\left(\mathrm{AUDPC}_{\text {standard }}\right)$, and coleoptile length reduction were evaluated. Regarding $\mathrm{AUDPC}_{\text {standard, }}$ intra- and inter-species variability in aggressiveness was detected. The other two aggressiveness criteria did not distinguish fungal isolates within and among species. It seems that $\mathrm{AUDPC}_{\text {standard }}$ may be used to measure aggressiveness of FHB on wheat at early stages. The three aggressiveness parameters were not significantly correlated. Cultivar-specific aggressiveness has not been detected. It was not possible to cluster the isolates based on their species origins because of similarity in pathogenic level among the 16 fungal isolates. Bread wheat was more resistant to FHB infection than durum wheat in vitro. The two tested modern cultivars were shown to exhibit moderate to high FHB resistance levels.
\end{abstract}

Keywords: bread and durum wheat, FHB variation, Syrian wheat cultivars

\section{Introduction}

Fusarium head blight (FHB) is one of the most destructive global diseases of bread and durum wheat. Since it was identified in 1884, severe epidemic outbreaks caused quantitative losses in yield of up to 50-75\% (Parry et al. 1995). It also reduces grain quality due to contamination of harvest with large amount of mycotoxins that cause toxicities to human and livestock (Palazzini et al. 2015). More than 17 Fusarium species have been isolated from naturally infected wheat spikes (Parry et al. 1995). The members of the F. graminearum sensu lato are reported as the most frequently recovered from wheat ears (O’Donnell et al. 2004). Also, other FHB causal agents are less frequently associated with FHB incidence (Xu et al. 2008). The spectrum of Fusarium spp. involved in the disease varies at a local or regional level depending on specific climatic conditions, agricultural practices, effectiveness of used fungicides and host resistance $(\mathrm{Xu}$ and $\mathrm{Ni}$ cholson 2009).

\footnotetext{
*Corresponding author; E-mail: ascientific6@aec.org.sy
} 
Aggressiveness is an attribute of a pathogen originally defined as the extent to which it can attack a susceptible host. For a given FHB species, aggressiveness is not geographically structured since isolates with low, medium, and high levels of aggressiveness make up the population in a single location (Xu and Nicholson 2009). Comprehension of the aggressiveness variability is crucial for disease management. More aggressive FHB species and/or isolates will reach a specific disease level faster. Resistance of wheat to FHB is a character controlled by a polygenic system (quantitative trait loci detected on all chromosomes), and isolate-specific resistance has not been detected (Spanic et al. 2013).

Wide epidemics of FHB have been recorded after the spread of modern wheat cultivars with excellent agronomic traits because of losing plant resistance during breeding process (Goral et al. 2008), However, some commercial wheat cultivars can exhibit an acceptable FHB resistance (Ban et al. 2008; Chrpova et al. 2012). But, linkage drag of the major Chinese Sumai 3 resistance QTL hampers their deployment in modern cultivars (Steiner et al. 2017).

Wheat domestication has occurred between 12,000 and 10,000 years BP in Syria. Wheat is one of the most important crops occupying up to 1.7 million hectares with more than 4 million tones in 2011 (FAO/WFP, 2015). Thereby, Syrian wheat cultivars including the modern ones may constitute a valuable genetic resource, possessing various desirable agronomic traits, including acceptable-level resistance to FHB. To date, some in vitro and growth chamber studies have reported the evaluation of aggressiveness of local FHB pathogens and resistance of wheat cultivars (Alazem 2007; Bakri et al. 2012; Sakr 2017a,b, 2018a). Notwithstanding, disease responses assessed with an in vitro tolls of FHB complex on modern Syrian wheat cultivars has not been reported yet. The objective of this study was to investigate pathogenicity using an in vitro Petri-dish test of four FHB species towards two modern Syrian durum and bread cultivars.

\section{Materials and Methods}

\section{Fungal isolates and wheat cultivars}

The 16 fungal isolates of four FHB species (F. culmorum (F1, F2, F3, F28 and F30), F. verticillioides (F15, F16, F21 and F27), F. solani (F7, F20, F26, F29, F31 and F35), and F. equiesti (F43)) were collected during the 2015 growing season from naturally growing wheat spikes with symptoms such as ear blight and bleached grains on ears in several locations of Ghab Plain, one of the principal Syrian wheat production areas. Although F. graminearum is considered the major causative of FHB disease, this species was not found in the surveyed region. Isolates were identified morphologically (Figure 1) according to Nelson et al. (1983). The cultures were maintained in sterile distilled water at $4{ }^{\circ} \mathrm{C}$ and by freezing at $-16{ }^{\circ} \mathrm{C}$ until needed (Sakr 2018b).

Two modern Syrian bread wheat Bohoth10 and durum wheat Cham 9 cultivars were used to characterize aggressiveness of 16 FHB isolates. Syrian check lines exhibiting several levels of quantitative resistance detected using an in vitro Petri-dish test and head inoculation under controlled conditions were used for validation tests. Cham4 and Dou- 
ma4 (bread cultivars) were more resistant to FHB infection than Cham7 and Acsad65 (durum cultivars) using the same fungal isolated involved in the present research (Sakr unpublished data).
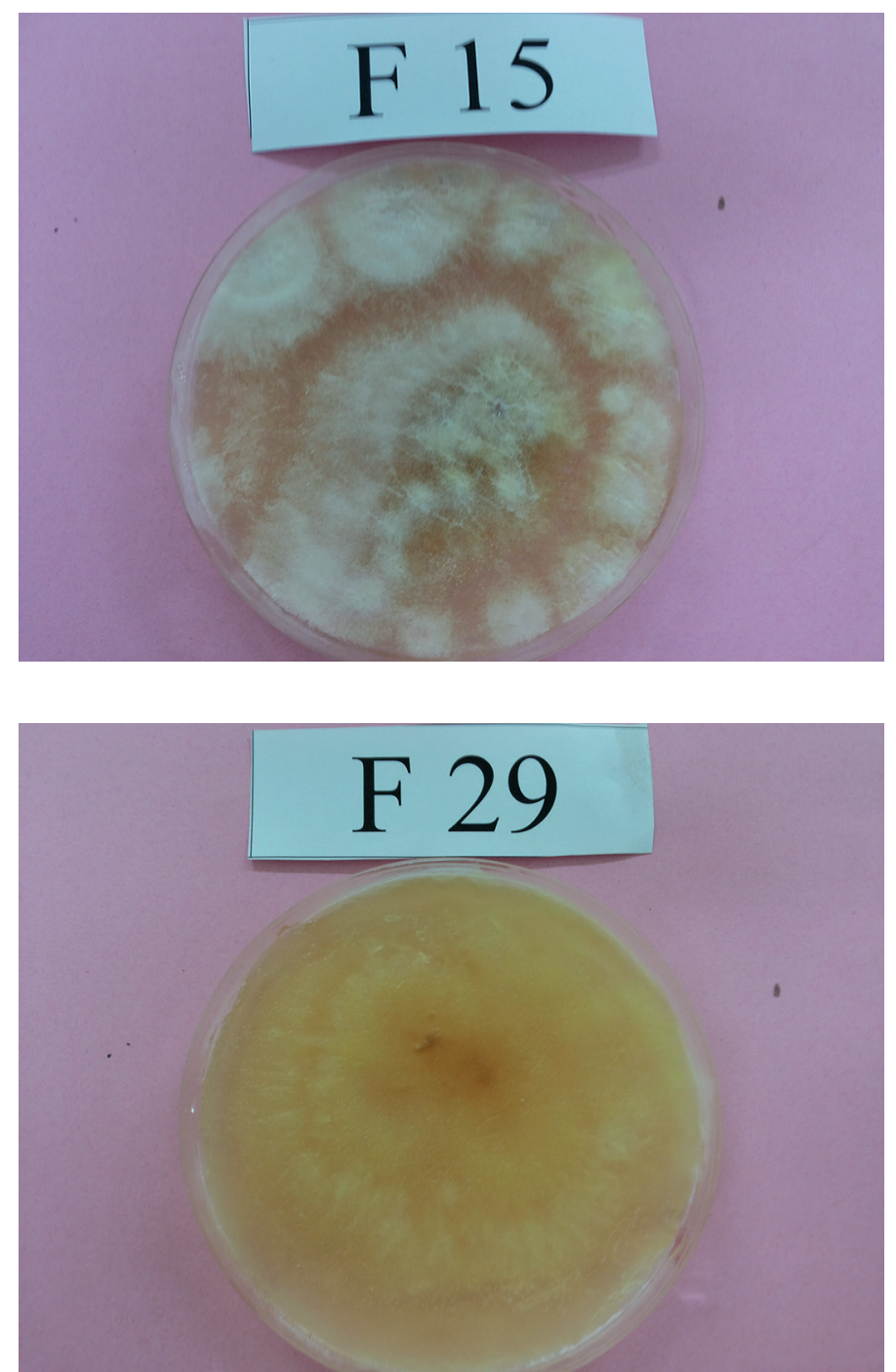

Figure 1. Two Fusarium head blight isolates on Petri-dish with potato-dextrose agar used for aggressiveness tests on wheat cultivars: F15 (F. verticillioides) and F29 (F. solani) 


\section{Aggressiveness tests}

Aggressiveness tests were done as per Purahong et al. (2012). Sterilized wheat seeds of Bohoth 10 and Cham9 were inoculated with a suspension of conidia (at $1 \times 10^{6}$ conidia per $\mathrm{ml}$ or sterile distilled water in the control treatment) for 16 fungal isolates in Petri-dishes with sterile double-layer filter paper, and arranged in a complete randomized design with three replicates. Three Petri-dishes per replicate were left non-inoculated as a control treatment. Three aggressiveness criteria: germination rate reduction, standardized area under disease progress curve $\left(\mathrm{AUDPC}_{\text {standard }}\right)$, and coleoptile length reduction were evaluated. Three replicates of each isolate were set up, and the experiment was repeated. Infected and control treatments were incubated in an incubator at $22{ }^{\circ} \mathrm{C}$ in the dark. Germination rate reduction and coleoptile length reduction were determined by comparison with the control treatment at 6 days after inoculation (DAI). The percentage of healthy coleoptiles was plotted as a function of time (from 2 to 6 DAI) and the area under healthy tissue progress curve (AUHPC) was calculated. AUHPC ranges from 50 (very aggressive, all seedlings diseased on day 3) to 400 (not aggressive, no diseased seedlings). AUHPC can be transformed to $\mathrm{AUDPC}_{\text {standard: }}$ the value ranges from 0 (not aggressive) to 1 (very aggressive).

\section{Statistical analyses}

Data were analyzed using StatView, $4.57^{\circledR}$ Abacus Concepts, Berkley, Canada. Before statistical analysis, germination rate reduction and coleoptile length reduction percentages were transformed using the Arcsines function. ANOVA incorporating the Fisher's LSD test at $\mathrm{P}=0.05$ was used to differentiate the means. The sample correlation coefficients (Pearson $\mathrm{r}$ ) were calculated using overall mean values per isolates at $\mathrm{P}=0.05$.

\section{Results}

Compared to the water control, seedlings of Bohoth10 and Cham9 wheat plants growing in the presence of 16 tested fungal isolates showed brown spots on the coleoptiles and/or mycelium completely covering the seeds, typical in vitro FHB symptoms (Purahong et al. 2012), suggesting a strong effect of FHB species complex on the growth of these cultivars.

Table 1 presents aggressiveness characteristics of FHB isolates on two wheat cultivars, Bohoth10 and Cham9. Exposure of wheat seeds to FHB species reduced mean seed germination value by $80 \%$ relative to the water control; it ranged from 19.3 to $22.5 \%$. The diseased coleoptiles were only one half of the mean lengths of healthy coleoptiles that reached $9.4 \mathrm{~mm}$ on Bohoth 10 and $10.9 \mathrm{~mm}$ on Cham9 whatever was the FHB isolate; it varied from 54.9 to $58.8 \%$. No significant differences were observed (F cultivars $=0.357$ $\mathrm{ns} ; \mathrm{P}=0.5521)$ in germination rate reduction $(\mathrm{GRR})$ on the two tested cultivars. Mean germination rate reduction on Cham 9 was $21.4 \%$ and on Bohoth10 was $20.7 \%$. There were no differences ( $\mathrm{F}$ cultivars $=0.555 \mathrm{~ns} ; \mathrm{P}=0.4591$ ) in coleoptile length reduction 


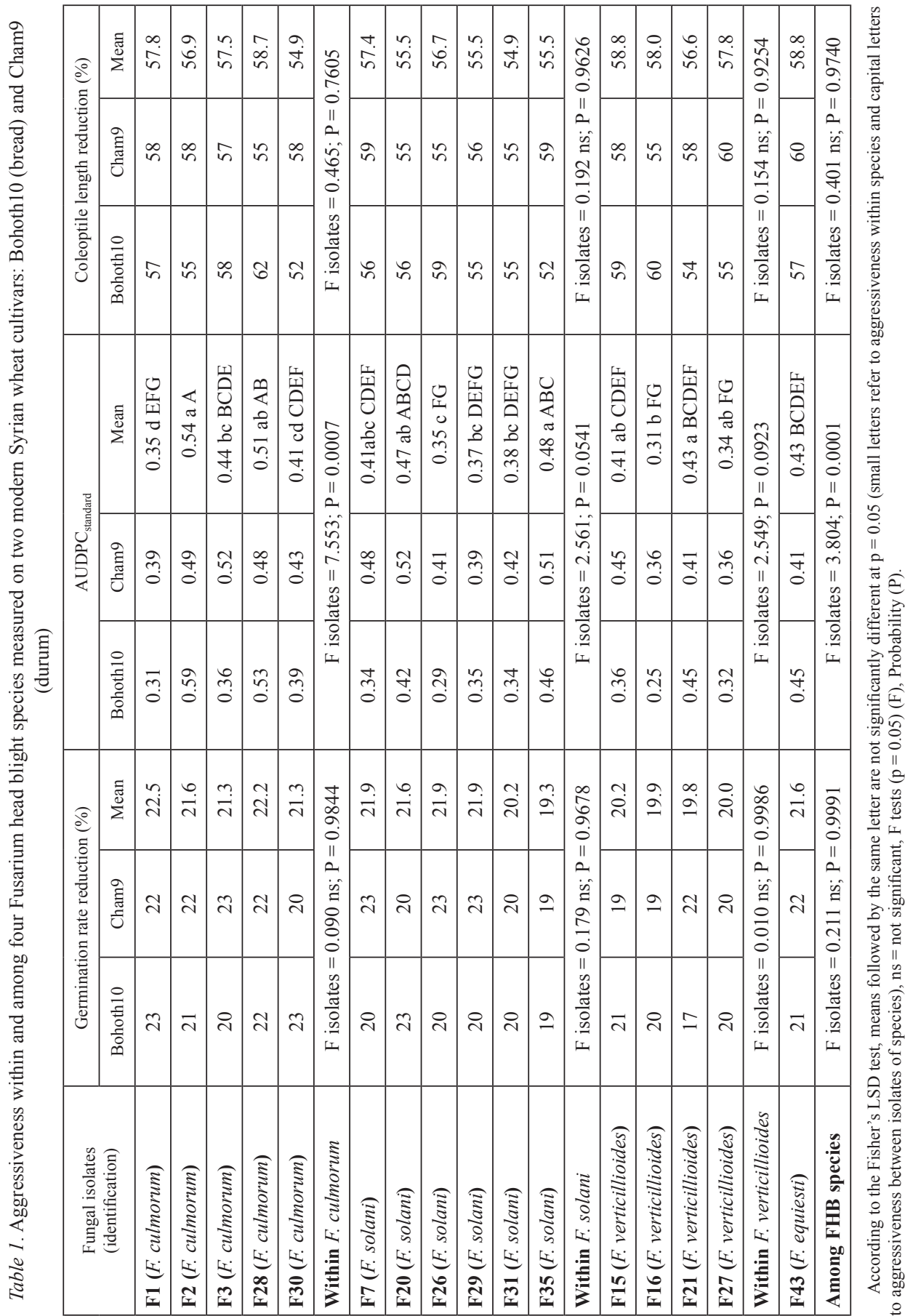


(CLR) on the two tested cultivars. Mean coleoptile length reduction on Cham9 was $57.3 \%$ and on Bohoth 10 was $56.6 \%$. For these two aggressiveness criteria, there were no significant differences in aggressiveness intra- and inter-species and in susceptibility between wheat cultivars.

The mean values of $\mathrm{AUDPC}_{\text {standard }}$ did differentiate within and among differences of aggressiveness in four FHB species and between the two tested wheat cultivars. Within F. culmorum species, the lowest $\mathrm{AUDPC}_{\text {standard }}$ value $(0.35)$ occurred for $\mathrm{F} 1$, whereas the most aggressive isolate F2, with value (0.54). Within $F$. solani species, F26 gave the least $\mathrm{AUDPC}_{\text {standard }}(0.35)$, while F35 (0.49) was significantly more aggressive. Within $F$. verticillioides species, the least AUDPC $_{\text {standard }}$ value was for F16 (0.31), and the most aggressive isolate was F21 (0.43). There were significant differences in the variation of aggressiveness among the isolates from the four FHB species. The isolate F2 (F. culmorum) showed the greatest aggressiveness, while F26 (F. solani) and F15 and F27 (F. verticillioides) were the least aggressive isolates. However, the $\mathrm{AUDPC}_{\text {standard }}$ differences among 16 isolates can not be used to distinguish the four FHB species, for example, isolates F3 and F30 (F. culmorum), F7 and F20 (F. solani), F15 and F21 (F. verticillioides), and F43 (F. equiesti) were not significantly different. Significant differences were underlined for

Table 2. Significancy of P-values for aggressiveness criteria within and among four FHB species measured on four wheat check lines: Cham4 (Ch.4), Douma4 (Do.4), Cham7

(Ch.7) and Acsad65 (Ac.65) (Sakr unpublished data)

\begin{tabular}{|c|c|c|c|c|}
\hline & \multicolumn{4}{|c|}{ Germination rate reduction $(\%)$} \\
\hline & Ch. 4 & Do. 4 & Ch.7 & Ac. 65 \\
\hline Within F. culmorum & NS & NS & NS & NS \\
\hline Within F. culmorum & NS & NS & NS & NS \\
\hline Within F. verticillioides & NS & NS & NS & NS \\
\hline \multirow[t]{3}{*}{ Among FHB species } & NS & NS & NS & NS \\
\hline & \multicolumn{4}{|c|}{ AUDPC $_{\text {standard }}$} \\
\hline & Ch.4 & Do. 4 & Ch.7 & Ac. 65 \\
\hline Within F. culmorum & $\mathrm{S}$ & $\mathrm{S}$ & $\mathrm{S}$ & $\mathrm{S}$ \\
\hline Within F. culmorum & $\mathrm{S}$ & $\mathrm{S}$ & $\mathrm{S}$ & $\mathrm{S}$ \\
\hline Within F. verticillioides & $\mathrm{S}$ & $\mathrm{S}$ & $\mathrm{S}$ & S \\
\hline \multirow[t]{3}{*}{ Among FHB species } & $\mathrm{S}$ & $\mathrm{S}$ & $\mathrm{S}$ & $\mathrm{S}$ \\
\hline & \multicolumn{4}{|c|}{ Coleoptile length reduction (\%) } \\
\hline & Ch.4 & Do. 4 & Ch.7 & Ac. 65 \\
\hline Within F. culmorum & NS & NS & NS & NS \\
\hline Within F. culmorum & NS & NS & NS & NS \\
\hline Within F. verticillioides & NS & NS & NS & NS \\
\hline Among FHB species & NS & NS & NS & NS \\
\hline
\end{tabular}

Significant (S) and not significant (NS) at $\mathrm{p}=0.05$. 
$\mathrm{AUDPC}_{\text {standard }}(\mathrm{F}$ cultivars $=9.862 ; \mathrm{P}=0.0026)$ among the two wheat cultivars. The mean values of $\mathrm{AUDPC}_{\text {standard }}$ evaluations ranged from 0.39 on Bohoth10 to 0.44 on Cham9.

Table 2 presents significancy of $\mathrm{P}$-values for aggressiveness criteria within and among four FHB species measured on wheat check lines (Sakr unpublished data). Regarding GRR and CLR, no significant differences in aggressiveness intra- and inter-species and in susceptibility among the four well known susceptible and resistant check lines were observed. However, AUDPC $_{\text {standard }}$ did distinguish within and among differences of aggressiveness in four FHB species and among the four wheat check lines. Also, the AUD$\mathrm{PC}_{\text {standard }}$ differences among 16 isolates can not be used to differentiate four FHB species on all wheat check lines.

The three parameters used with the Petri-dish test were not significantly correlated. GRR did not correlate significantly with $\mathrm{AUDPC}_{\text {standard }}(\mathrm{r}=0.111 \mathrm{~ns})$ and CLR $(\mathrm{r}=0.145 \mathrm{~ns})$. Also, there was no significant correlation between $\mathrm{AUDPC}_{\text {standard }}$ and CLR $(\mathrm{r}=-0.051 \mathrm{~ns})$.

\section{Discussion}

The loss of intensive selection pressures towards resistance to stresses and the conditions of the cultivation of plants used in breeding stations have caused modern wheat cultivars to be poorly adapted to biotic and abiotic stresses (Audenaert et al. 2014). The best economic and ecological strategies that reduce damage caused by FHB disease require knowledge of aggressiveness (Parry et al. 1995; Leonard and Bushnell 2003; Xu and Nicholson 2009). With this in mind, the variation of quantitative component of pathogenicity was analyzed in vitro for local FHB species on two modern durum and bread wheat cultivars recently planted in several Syrian locations. Disease development by FHB fungi is manifested via different experimental conditions involved in the Petri-dish assay which ensure that their aggressiveness is constant and/or correctly characterized or measured. All the 16 fungal isolates analyzed fulfilled the requirement of pathogenicity (ability to induce FHB disease), thus they are pathogenic.

High germination rate reduction, high $\mathrm{AUDPC}_{\text {standard }}$ values, and significant reduction in the length of the coleoptile represent high aggressiveness (Purahong et al. 2012). The two aggressiveness criteria, germination rate reduction and coleoptile length reduction did not distinguish fungal isolates within and among species. Also, no significant differences between the two wheat cultivars were detected. Our results are in accordance with the in vitro previous analysis (Sakr 2017b, 2018a) in which those aggressiveness criteria did not distinguish FHB isolates and wheat cultivars. Our results were in accordance with those reported by Purahong et al. (2012) for F. graminearum; they observed that reductions in germination rate were not significant. Brennan et al. (2003) noted that reduction of the coleoptile length has been related to aggressiveness. Purahong et al. (2012) found that this parameter differentiate fungal isolates.

The values of $\mathrm{AUDPC}_{\text {standard }}$ underlined a variation in aggressiveness within and among four FHB species. Moreover, AUDPC $_{\text {standard }}$ did differentiate between the two tested wheat cultivars. AUDPC standard $_{\text {was }}$ calculated from the decreasing number of healthy 
wheat seedlings after fungal inoculation of the seeds (Purahong et al. 2012). The faster the reduction of the number of healthy seedlings, the more aggressive is the fungal isolate (Purahong et al. 2012). Our results are in accordance with the in vitro previous analysis in which this criterion of aggressiveness did distinguish fungal isolates and wheat cultivars (Sakr 2017b, 2018a). Also, our findings are in accordance with those found by Bakri et al. (2012) in which significant differences were detected within three Syrian FHB species $F$. culmorum, F. solani and F. verticillioides collected from several Syrian regions using head inoculation under controlled conditions. Mutation, genetic recombination or selection may play a basic role in these differences in aggressiveness. In three FHB species: $F$. culmorum, $F$. verticillioides and $F$. solani obtained from wheat seeds showing FHB symptoms in different Syrian locations in 2007, high genotypic and aggressiveness variances within and among the three species were detected (Arabi and Jawhar 2010; Bakri et al. 2012). For the three aggressiveness criteria involved in Petri-dish test, pathogenic variation in 16 FHB isolates was validated with data generated on four well known susceptible and resistant wheat check lines.

The in vitro Petri-dish assay can distinguish the level of aggressiveness of four FHB species at early stages of plant growth by promoting the interaction between wheat tissues and fungi. The situation in the Petri-dish assay was identical to artificial inoculation under controlled conditions. FHB inoculum was put directly on the wheat seeds and they could directly penetrate and infect germinating seeds. Thus, disease development is manifested through appearance of typical in vitro symptoms (Purahong et al. 2012). It seems that AUDPC $_{\text {standard }}$ may be used to measure aggressiveness of FHB on wheat at early stages.

The three aggressiveness parameters were not significantly correlated, suggesting that these criteria are genetically distinct, and also reflecting into complex polygenic nature of aggressiveness in the interaction in FHP-wheat system. It seems that each individual aggressiveness criterion differentially influences aspect of FHB disease development in wheat plants. Our data agree with those found by Sakr (2018a) on barley plants. However, results obtained in this study do not correspond with those obtained by Purahong et al. (2012); they noticed a correlation among the three aggressiveness parameters. Interestingly, cultivar-specific aggressiveness has not been detected. Significant correlation was detected between the values of AUDPC $_{\text {standard }}$ for the two tested wheat cultivars infected with 16 fungal isolates $\left(\mathrm{r}=0.559^{*}\right)$. In this pathosysteme, no strong evidence for speciesspecific in wheat to any of the fungal species implicated in the FHB complex (Parry et al. 1995).

It was not possible to cluster the isolates based on their species origins because of similarity in pathogenic level among the 16 fungal isolates. The origin of FHB cultures may play a crucial role in this pathogenic similarity. The tested isolates of $F$. culmorum, $F$. verticillioides, F. solani, and F. equiesti species collected from Ghab plain, a limited geographic area, may exhibit low degrees of gene/genotype flow which result in low mutation and population size levels, and consequently these physiological and genetic characteristics may increase the level of pathogenic similarity between species as observed for other pathogens (McDonald and Linde 2002). 
Durum wheat is more susceptible to FHB infection than bread wheat (Spanic et al. 2013). Quantitative resistant wheat cultivars are identified by low AUDPC $_{\text {standard }}$ values of the fungus compared with the susceptible one (Purahong et al. 2012). AUDPC standard $_{\text {rat- }}$ ing for the two wheat cultivars reflects the ability of the same isolate of the pathogen to differentiate several levels of resistance as observed for the same pathosystem (Alazem 2007). Also, the resistance of a given wheat cultivar is not related to a certain FHB species. Bohoth10 was more resistant to FHB infection than Cham9 in vitro. Wheat cultivar Cham9 exhibited an increase of AUDPC $_{\text {standard }}$ values (more than 11\%) as compared with Bohoth10. The values of $\mathrm{AUDPC}_{\text {standard }}$ criterion recorded a clear variation depending on fungal isolates and wheat cultivars. The lowest $\mathrm{AUDPC}_{\text {standard }}$ value $(0.25)$ occurred for $\mathrm{F} 16$ (F. verticillioides) on Bohoth10 and the least $\mathrm{AUDPC}_{\text {standard }}$ value was for $\mathrm{F} 16$ and F27 (F. verticillioides) (0.36) on Cham9. While the most aggressive isolates F2 (F. culmorum) with value $(0.59)$ on Bohoth10 and F3 (F. culmorum) $(0.52)$ were more aggressive on Cham9. The two tested modern Syrian cultivars were shown to exhibit moderate to high resistance levels to in vitro FHB infection. However, the moderately resistant level in the two cultivars made it possible to detect intra- and inter-significant differences in aggressiveness. Taking into consideration that breeding programs is hampered by the narrow genetic variation for FHB resistance in durum wheat and alternative sources of resistance have been screened in bread wheat to identify resistance donors for breeding (Steiner et al. 2017); Cham9 (durum) and Bohoth10 (bread) could be considered as promising resistance sources to FHB for introgression in the adapted wheat gene pool. It will be necessary to analyze the pathogenic reaction of available modern Syrian bread and durum wheat cultivars in vitro, under controlled and field conditions to screen levels of resistance in Syrian wheat cultivars.

\section{Acknowledgements}

The author would like to thank Director General of AECS and the Head of the Agriculture Department for their support.

\section{References}

Alazem, M. 2007. Evaluating genetic variation of Fusarium head blight by molecular markers. Master, University of Damascus, DAM, Syria.

Arabi M.I.E., Jawhar, M. 2010. Heterogeneity in Fusarium species as revealed by Inter-retrotransposon amplified polymorphism (IRAP). J. Plant Pathol. 92:751-755.

Audenaert, K., Troch, V., Landschoot, S., Haesaert, G. 2014. Biotic stresses in the anthropogenic hybrid triticale ( $\times$ Triticosecale Wittmack): Current knowledge and breeding challenges. Eur. J. Plant Pathol. 140:615630.

Bakri, Y., Jawhar, M., Arabi, M.I.E. 2012. Correlative analysis of Fusarium species pathogenicity and in vitro xylanase activity. J. Plant Biol. Res. 1:86-92.

Ban, T., Kawad, N., Yanagisawag, A., Takezaki, A. 2008. Progress and future prospects of resistance breeding to Fusarium head blight in Japan. Cereal Res. Commun. 36:23-29.

Brennan, J.M., Fagan, B., van Maanen, A., Cooke, B.M., Doohan, F.M. 2003. Studies on in vitro growth and pathogenicity of European Fusarium fungi. Eur. J. Plant Pathol. 109: 577-587. 
Chrpova, J., Sip, V., Stockova, L., Dumalasova, V. 2012. Evaluation of Fusarium head blight resistance in wheat under high infection pressure in field conditions. Cereal Res. Commun. 40:396-404.

FAO/WFP, 2015. Crop and food security assessment mission to the Syrian Arab Republic. [cited 2015 July 23] Available from: http:/www.wfp.org/foodsecurity/reports/CFSAM.

Goral, T., Ochodzki, P., Mazurek, A., Bulinskaradomska, Z. 2008. Resistance of species from genus Triticum to Fusarium head blight and accumulation of Fusarium-metabolites in grain. Cereal Res. Commun. 36:9597.

Leonard, K.J., Bushnell, W.R. 2003. Fusarium Head Blight of Wheat and Barley. The American Phytopathological Society, St. Paul, USA, 512 pp.

McDonald, B. A., Linde, C. 2002. The population genetics of plant pathogens and breeding strategies for durable resistance. Euphytica 124:163-180.

Nelson, P.E., Toussoun, T.A., Marasas, W.F.O. 1983. Fusarium Species: An Illustrated Manual for Identification. The Pennsylvania State Univ. Press, Pennsylvania, USA, 193 pp.

O’Donnell, K., Ward, T.J., Geiser, D.M., Kistler, H.C., Aoki, T. 2004. Genealogical concordance between the mating type locus and seven other nuclear genes supports formal recognition of nine phylogenetically distinct species within the Fusarium graminearum clade. Fungal Genet. Biol. 41:600-623.

Palazzini, J., Fumero, V., Yerkovich, N., Barros, G., Cuniberti, M., Chulze. S. 2015. Correlation between Fusarium graminearum and deoxynivalenol during the 2012/13 wheat Fusarium head blight outbreak in Argentina. Cereal Res. Commun. 43:627-637.

Parry, D.W., Jekinson, P., MCleod, L. 1995. Fusarium ear blight (scab) in small grain cereals-a review. Plant Pathol. 44:207-238.

Purahong, W., Alkadri, D., Nipoti, P., Pisi, A., Lemmens, M., Prodi, A. 2012. Validation of a modified Petri-dish test to quantify aggressiveness of Fusarium graminearum in durum wheat. Eur. J. Plant Pathol. 132:381391.

Sakr N. 2017a. Aggressiveness of four Fusarium head blight species on wheat cultivars. Adv. Hortic Sci. 31:199-203.

Sakr, N. 2017b. In vitro assessment of Fusarium head blight spp. on wheat cultivars. Arch. Phytopathol. Plant Protect. 50:254-261.

Sakr N. 2018a. Aggressiveness variation among and within Fusarium head blight species on barley in vitro. Acta Phytopathol. et Entomol. Hung. DOI: 10.1556/038.52.2017.033.

Sakr N. 2018b. Evaluation of two storage methods for fungal isolates of Fusarium sp. and Cochliobolus sativus. Acta Phytopathol. et Entomol. Hung. DOI: 10.1556/038.53.2018.003.

Spanic, V., Lemmens, M., Drezner, G. 2013. Variability in components of fusarium head blight resistance among wheat genotypes. Cereal Res. Commun. 41:420-430

Steiner, B., Buerstmayr, M., Michel, S., Schweiger, W., Lemmens, M., Buerstmayr, H. 2017. Breeding strategies and advances in line selection for Fusarium head blight resistance in wheat. Trop. Plant Pathol. 42:165-174.

Xu, X., Nicholson, P. 2009. Community ecology of fungal pathogens causing wheat head blight. Annu. Rev. Phytopathol. 47:83-103.

Xu, X.M., Parry, D.W., Nicholson, P., Thomsett, M.A., Simpson, D., Edwards, S.G., Cooke, B., MDoohan, F.M., Monaghan, S., Moretti, A., Tocco, G., Mule, G., Hornok, L., Beki, E., Tantnell, J., Ritieni, A. 2008. Within field variability of Fusarium head blight pathogens and their associated mycotoxins. Eur. J. Plant Pathol. 120:21-34. 